\title{
PENGARUH DUKUNGAN SUAMI TERHADAP KEBERHASILAN PEMBERIAN ASI EKSKLUSIF DI RB SOEGIARTI SURABAYA
}

\author{
Supartini \\ Prodi DIII Kebidanan, Universitas PGRI Adi Buana Surabaya \\ Email:supartinisamsuri53@yahoo.com
}

\begin{abstract}
ABSTRAK
ASI merupakan sumber gizi yang ideal dengan komposisi yang seimbang dan disesuaikan dengan kebutuhan pada masa pertumbuhannya. Oleh karena itu pemberian ASI merupakan cara terbaik untuk meningkatkan kualitas sumber daya manusia pada saat awal, namun perlu diimbangi dengan pemberian yang benar dan pemanfaatan kolostrum serta pemberian ASI secara dini setelah bayi lahir, yang diteruskan dengan ASI Eksklusif sampai umur 6 bulan dan ASI dilanjutkan sampai umur 2 tahun. (Depkes RI, 2007). Pencapaian ASI Eksklusif di Kota Surabaya masih rendah dan mengalami penurunan setiap waktu. Berdasarkan data dari Puskesmas di Surabaya diketahui bahwa cakupan bayi yang mendapat ASI Eksklusif di Kota Surabaya tahun 2010 sebesar 26,90\% dan yang tidak mendapat ASI Eksklusif sebesar 73,10\% (Profil Kesehatan Jawa Timur 2010). Keterlibatan suami dalam mendukung praktik pemberian ASI eksklusif pada bayi di Indonesia sangat minim. Dukungan suami sangat diperlukan agar pemberian ASI eksklusif bisa tercapai. Penelitian ini bertujuan mengetahui pengaruh dukungan suami terhadap keberhasilan pemberian ASI Eksklusif. Dalam Penelitian ini digunakan metode analitik dengan desain cross sectional. Populasi dalam penelitian ini adalah ibu menyusui dengan bayi $\geq 6$ bulan di RB Sugiarti Surabaya, periode Oktober 2015 - Desember 2015 . Sampel dalam penelitian ini sebanyak 25 responden yang pengambilannya menggunakan teknik accidental sampling. Data penelitian ini di ambil menggunakan kuesioner, selanjutnya pengaruh antar variabel di analisis dengan uji Chi - Kuadrat dengan tingkat kemaknaan 0,05.Berdasarkan hasil penelitian dari 25 responden, keberhasilan pemberian ASI Eksklusif terbanyak dari 16 responden ( 64 $\%$ ) yang mendapat dukungan suami sebanyak 12 responden ( $48 \%$ ). Setelah dilakukan Uji Chi - Kuadrat pada tabel dapat disimpulkan $\chi^{2}$ hitung $6,4>\chi_{\text {tabel }}^{2}$ 3,841, Ho ditolak yang berarti ada pengaruh dukungan suami terhadap keberhasilan pemberian ASI Eksklusif. Oleh sebab itu adanya duk ${ }^{\cdots}{ }^{-r a n}$ suami sangat penting untuk keberhasilan pemberian ASI Eksklusif, karena suami dapat memberika kenyamanan ibu untuk menyusui bayinya sehingga dapat meningkatkan produksi ASI. langan jiwa dan
\end{abstract}

Kata Kunci : Dukungan Suami, Keberhasilan Pemberian ASI Eksklusif.

\section{PENDAHULUAN}

ASI merupakan sumber gizi yang ideal dengan komposisi yang seimbang dan disesuaikan dengan kebutuhan pada masa pertumbuhannya. Oleh karena itu pemberian ASI merupakan cara terbaik untuk meningkatkan kualitas sumber daya manusia pada saat awal, namun perlu diimbangi dengan pemberian yang benar dan pemanfaatan kolostrum serta pemberian ASI secara dini setelah bayi lahir, yang diteruskan dengan ASI Eksklusif sampai umur 6 bulan dan ASI dilanjutkan sampai umur 2 tahun. (Depkes RI, 2007).
Penggunaan ASI saat ini belum seperti yang kita harapkan. Hasil survei Demografi dan Kesehatan Indonesia (SDKI) tahun 2002-2003, menunjukkan bahwa ibu-ibu yang memberikan ASI Eksklusif pada bayinya dibawah usia 2 bulan masih lumayan banyak (64\% dari total bayi yang ada). Namun, prosentase tersebut menurun seiring dengan bertambahnya usia bayi, yakni hanya $46 \%$ pada bayi usia 2-3 bulan dan 14\% pada bayi usia 4-5 bulan. Berdasarkan SDKI 2007, angka cakupan ASI Eksklusif 6 bulan di Indonesia hanya 
$32,30 \%$, masih jauh dari rata-rata dunia yaitu $38 \%$. Sementara itu, saat ini jumlah bayi di bawah 6 bulan yang diberi susu formula meningkat dari $16,70 \%$ pada tahun 2002 menjadi $27,90 \%$ pada tahun 2007 (SDKI, 2007).

Menurut data dari Dinkes Jatim 2003 pencapaian pemberian ASI masih mencapai 47,42\%, sedangkan tahun 2004 didapat 43,91\%. Data dari Kabupaten/Kota diketahui bahwa cakupan bayi yang mendapat ASI Eksklusif di Jawa Timur tahun 2010 sebesar 30,72\% dan yang tidak mendapat ASI Eksklusif sebesar 69,28\% (Profil Kesehatan Jawa Timur, 2009).

Pencapaian ASI Eksklusif di Kota Surabaya masih rendah dan mengalami penurunan setiap waktu. Berdasarkan data dari Puskesmas di Surabaya diketahui bahwa cakupan bayi yang mendapat ASI Eksklusif di Kota Surabaya tahun 2010 sebesar 26,90\% dan yang tidak mendapat ASI Eksklusif sebesar 73,10\% (Profil Kesehatan Jawa Timur 2010).

Bila dibandingkan dengan target pada Standart Pelayanan Minimal (SPM) di Kabupaten/Kota, di mana target pencapaian ASI Eksklusif adalah 80\% pada tahun 2010 (Kepmenkes, 2004), juga berdasarkan target Indonesia Sehat 2010 bahwa persentase bayi yang mendapat ASI Eksklusif adalah 80\% (Depkes, 2003), maka pencapaian di Kota Surabaya tersebut masih sangat rendah.

Menurut Dirjen Gizi dan KIA, keberhasilan ibu menyusui untuk terus menyusui bayinya sangat ditentukan oleh dukungan dari suami, keluarga, petugas kesehatan, masyarakat serta lingkungan kerja (Budiharja, 2011). Menurut Utami Roesli (2008), terdapat tujuh langkah keberhasilan pemberian ASI Eksklusif salah satunya adalah menciptakan dukungan suami. Keterlibatan suami dalam mendukung praktik pemberian ASI eksklusif pada bayi di Indonesia sangat minim. Dukungan suami sangat diperlukan agar pemberian ASI eksklusif bisa tercapai. Sejauh ini, suami kebanyakan hanya berperan dalam pemilihan tempat pemeriksaan kehamilan, persalinan, dan pascapersalinan atau imunisasi.

Oleh karena itu, peran suami sebaiknya jadi salah satu kelompok sasaran dalam kampanye pemberian ASI eksklusif harus ditingkatkan, serta saling berkomunikasi di setiap kegiatan promosi harus ditujukan kepada mereka berdua sebagai satu kesatuan. Dan berbagai saluran informasi untuk dapat menyentuh suami dalam promosi tentang proses menyusui harus digunakan.
Berdasarkan data diatas penulis tertarik untuk melakukan penelitian tentang pengaruh dukungan suami terhadap keberhasilan pemberian ASI Eksklusif.

Rumusan Masalah adalah :

1. Bagaimana dukungan suami terhadap keberhasilan pemberian ASI Eksklusif?

2. Bagaimana keberhasilan pemberian ASI Eksklusif?

3. Apakah dukungan suami berpengaruh dalam keberhasilan pemberian ASI Eksklusif?

Tujuan penelitian adalah

1. Mengidentifikasi dukungan suami terhadap keberhasilan pemberian ASI Eksklusif.

2. Mengidentifikasi keberhasilan pemberian ASI Eksklusif.

3. Menganalisis pengaruh dukungan suami terhadap keberhasilan pemberian ASI Eksklusif.

\section{METODE PENELITIAN}

Dalam Penelitian ini digunakan metode analitik dengan desain cross sectional.

Populasi dalam penelitian ini adalah ibu menyusui dengan bayi $\geq 6$ bulan di RB Sugiarti Surabaya, periode Oktober 2015 - sember 2015 . Sampel dalam penelitian ini sebanyak 25 responden yang pengambilannya menggunakan teknik accidental sampling.

Pengumpulan data penelitian ini di ambil menggunakan kuesioner, selanjutnya pengaruh antar variabel di analisis dengan uji Chi - Kuadrat dengan tingkat kemaknaan 0,05.

\section{HASIL DAN PEMBAHASAN DATA UMUM}

Dibawah ini akan disajikan data umum yang meliputi karakteristik responden berdasarkan umur, paritas, pendidikan, dan pekerjaan.

1. Berdasarkan Umur Ibu menyusui dan suami 2. 
Tabel 1. Karakteristik Responden Berdasarkan Umur ibu menyusui bayi $\geq 6$ bulan yang datang di RB Soegiarti Bulan Oktober - Desember 2015

\begin{tabular}{cccc}
\hline No & $\begin{array}{c}\text { Umur } \\
\text { (Tahun) }\end{array}$ & Jumlah & $\begin{array}{c}\text { Prosentasi } \\
(\mathbf{\%})\end{array}$ \\
\hline 1 & $<20$ & 2 & 8 \\
\hline 2 & $20-30$ & 13 & 52 \\
\hline 3 & $\geq 30$ & 10 & 40 \\
\hline & Jumlah & 25 & 100 \\
\hline
\end{tabular}

Sumber : Data Primer, 2015

Berdasarkan tabel 1 di atas menunjukkan dari 25 responden umur ibu menyusui bayi $\geq 6$ bulan yang datang di RB Soegiarti pada bulan Oktober - Desember 2015 paling banyak adalah umur 20-30 tahun sebanyak 13 responden $(52 \%)$.

Tabel .2 $\quad$ Karakteristik Responden Berdasarkan Umur suami ibu menyusui bayi $\geq 6$ bulan yang datang di RB Soegiarti bulan Oktober - Desember 2015

\begin{tabular}{cccc}
\hline No & $\begin{array}{c}\text { Umur } \\
\text { (Tahun) }\end{array}$ & Jumlah & $\begin{array}{c}\text { Prosentasi } \\
(\mathbf{\%})\end{array}$ \\
\hline 1 & $<20$ & 0 & 0 \\
\hline 2 & $20-30$ & 12 & 48 \\
\hline 3 & $\geq 30$ & 13 & 52 \\
\hline & Jumlah & 25 & 100 \\
\hline
\end{tabular}

Sumber : Data Primer, 2015

Berdasarkan tabel .2 di atas menunjukkan dari 25 responden umur suami ibu menyusui bayi $\geq 6$ bulan yang datang di RB Soegiarti bulan Oktober - Desember 2015 paling banyak adalah umur $\geq 30$ tahun sebanyak 13 responden $(52 \%)$.

3. Berdasarkan pendidikan Ibu menyusui dan suami

Tabel 3. Karakteristik Responden Berdasarkan Pendidikan ibu menyusui bayi $\geq 6$ bulan yang datang di RB Soegiarti bulan Oktober - Desember 2015.

\begin{tabular}{cccc}
\hline No & Pendidikan & Jumlah & $\begin{array}{c}\text { Prosentasi } \\
(\mathbf{\%})\end{array}$ \\
\hline 1 & $\begin{array}{c}\text { Tidak } \\
\text { Sekolah }\end{array}$ & 2 & 8 \\
\hline 2 & SD & 2 & 8 \\
\hline 3 & SMP & 9 & 36 \\
\hline 4 & SMA & 10 & 40 \\
\hline 5 & $\begin{array}{c}\text { Perguruan } \\
\text { Tinggi }\end{array}$ & 2 & 8 \\
\hline & Jumlah & 25 & 100 \\
\hline
\end{tabular}

Sumber : Data Primer, 2015

Berdasarkan tabel 3 di atas menunjukkan dari 25 responden Pendidikan ibu menyusui bayi $\geq 6$ bulan yang datang di RB Soegiarti bulan Oktober - Desember 2015 paling banyak adalah SMA sebanyak 10 responden ( $40 \%$ )

Tabel 4. Karakteristik Responden Berdasarkan Pendidikan suami ibu menyusui bayi $\geq 6$ bulan yang datang di RB Soegiarti bula Oktober - Desember 2015.

\begin{tabular}{cccc}
\hline No & Pendidikan & Jumlah & $\begin{array}{c}\text { Prosentasi } \\
(\%)\end{array}$ \\
\hline 1 & $\begin{array}{c}\text { Tidak } \\
\text { Sekolah }\end{array}$ & 3 & 13 \\
\hline 2 & SD & 2 & 8 \\
\hline 3 & SMP & 6 & 24 \\
\hline 4 & SMA & 12 & 48 \\
\hline 5 & $\begin{array}{c}\text { Perguruan } \\
\text { Tinggi }\end{array}$ & 1 & 4 \\
\hline & Jumlah & 25 & 100 \\
\hline
\end{tabular}

Sumber : Data Primer, 2015

Berdasarkan tabel 4. di atas menunjukkan dari 25 responden Pendidikan suami ibu menyusui bayi $\geq 6$ bulan yang datang di RB Soegiarti bulan Oktober - Desember 2015 paling banyak adalah SMA sebanyak 12 responden $(48 \%)$.

4. Berdasarkan Pekerjaan Suami dan Ibu Menyusui

Tabel.5 Karakteristik Responden Berdasarkan Pekerjaan suami ibu menyusui bayi $\geq 6$ bulan yang datang di RB Soegiarti bulan Oktober-Desember 2015 


\begin{tabular}{cccc}
\hline No & Bekerja & Jumlah & $\begin{array}{c}\text { Prosentasi } \\
(\%)\end{array}$ \\
\hline 1 & Ya & 25 & 100 \\
\hline 2 & Tidak & 0 & 0 \\
\hline & Jumlah & 25 & 100 \\
\hline
\end{tabular}

Sumber : Data Primer, 2015

Berdasarkan tabel.5 di atas menunjukkan dari 25 responden Pekerjaan suami ibu menyusui bayi $\geq 6$ bulan yang datang di RB Soegiarti bula Oktober-Desember 2015 adalah semuanya bekerja sebanyak 25 responden ( $25 \%$ ).

Tabel.6 Karakteristik Responden Berdasarkan Pekerjaan ibu menyusui bayi $\geq 6$ bulan yang datang di RB Soegiarti bula Oktober -Desember 2015 .

\begin{tabular}{cccc}
\hline No & Bekerja & Jumlah & $\begin{array}{c}\text { Prosentasi } \\
(\mathbf{\%})\end{array}$ \\
\hline 1 & Ya & 11 & 44 \\
\hline 2 & Tidak & 14 & 56 \\
\hline & Jumlah & 25 & 100 \\
\hline
\end{tabular}

Sumber : Data Primer, 2015

Berdasarkan tabel.6 di atas menunjukkan dari 25 responden Pekerjaan ibu menyusui bayi $\geq 6$ bulan yang datang di RB Soegiarti bulan Oktober-Desember 2015 paling banyak adalah tidak bekerja sebanyak 14 responden ( $56 \%$ ).

5. Berdasarkan Paritas

Tabel.7 Karakteristik Responden Berdasarkan Paritas ibu menyusui bayi $\geq$ 6 bulan yang datang di RB Soegiarti bulan Oktober- Desember 2015

\begin{tabular}{cccc}
\hline No & Paritas & Jumlah & $\begin{array}{c}\text { Prosentasi } \\
(\mathbf{\%})\end{array}$ \\
\hline 1 & Primigravida & 8 & 32 \\
\hline 2 & Multigravida & 13 & 52 \\
\hline 3 & $\begin{array}{c}\text { Grandemulti } \\
\text { gravida }\end{array}$ & 4 & 16 \\
\hline & Jumlah & 25 & 100 \\
\hline
\end{tabular}

Sumber : Data Primer, 2015

Berdasarkan tabel .7 di atas menunjukkan dari 25 responden Paritas ibu menyusui bayi $\geq 6$ bulan yang datang di RB Soegiartibulan
Oktober - Desember 2015 tan paling banyak adalah multigravida sebanyak 13 responden $(52 \%)$.

\section{Data Khusus}

1. Dukungan Suami

Tabel .8 Distribusi Dukungan Suami Terhadap Keberhasilan Pemberian ASI Eksklusif di RB Soegiarti bulan OktoberDesember 2015

\begin{tabular}{cccc}
\hline No & $\begin{array}{l}\text { Dukungan } \\
\text { suami } \\
\text { terhadap } \\
\text { keberhasilan } \\
\text { pemberian } \\
\text { ASI Eksklusif }\end{array}$ & Jumlah & $\begin{array}{c}\text { Prosentasi } \\
\text { (\%) }\end{array}$ \\
\hline 1 & Ya & 14 & 56 \\
\hline 2 & Tidak & 11 & 44 \\
\hline & Jumlah & 25 & 100 \\
\hline
\end{tabular}

Sumber : Data Primer, 2015

Berdasarkan tabel.8 di atas menunjukkan dari 25 responden sebagian besar suami memberikan dukungan terhadap keberhasilan pemberian ASI Eksklusif sebanyak 14 responden $(56 \%)$.

Seorang suami mempunyai peran yang sangat penting dalam keberhasilan ibu menyusui, jika ibu merasa didukung, dicintai, dan diperhatikan, maka akan muncul emosi positif yang akan meningkatkan produksi hormon oksitosin sehingga produksi ASIpun menjadi lancar. Jadi, keberhasilan menyusui seorang ibu tidak hanya tergantung pada sang ibu sendiri, tetapi juga pada suami ibu. (Utami Roesli, 2008 :20) Dalam proses menyusui, selain hormon prolaktin, juga dibutuhkan hormon oksitosin yang berguna untuk mengeluarkan ASI. Oksitosin terbentuk saat bayi mulai menyusu atau saat ibu menerima rangsangan, seperti mendengar suara bayi menangis atau mengusap usap wajah bayi. Hormon oksitosin yang berguna dalam proses pengeluaran ASI, akan terbentuk ketika ibu merasa santai dan tenang. Ibu yang mendapat dukungan suami memiliki rasa nyaman dan merasa memiliki kemampuan untuk memberikan ASI eksklusif. Mereka memiliki kepercayaan yang lebih tinggi dalam kemampuan untuk menyusui, dibandingkan dengan ibu yang tidak memberi dukungan 
positif atau pasif. Dukungan dari suami dapat meningkatkan kepercayaan diri ibu untuk menyusui, terlepas dari ibu pernah menyusui atau belum.

Dukungan seorang suami yang berpikiran bahwa ASI adalah merupakan makanan bayi yang terbaik, akan membuat ibu lebih mudah memberikan ASI Eksklusif pada bayinya (Purwoko,2005)

Adapun suami yang tidak memberikan dukungan terhadap keberhasilan pemberian ASI Eksklusif disebabkan karena kesibukan di tempat kerja dan karena ketidaktahuan tentang ASI Eksklusif sehingga ia tidak mengerti apa yang harus dilakukan terhadap istri dan bayinya. Suami membutuhkan informasi yang jelas tentang cara memberi dukungan yang benar kepada istrinya yang sedang menyusui. Suami perlu mengetahui cara memberi dukungan dan belajar apa yang dibutuhkan istrinya untuk kenyamanan menyusui. Hal ini didukung oleh semua suami ibu menyusui bayi $\geq 6$ bulan di RB Soegiarti bekerja dan paling banyak pendidikan terakhir SMA.

\section{Keberhasilan ASI Eksklusif}

\begin{tabular}{|c|c|c|c|}
\hline $\begin{array}{l}\text { Tab } \\
\text { Pem } \\
\text { bula }\end{array}$ & $\begin{array}{l}9 \text { Distribu } \\
\text { rian ASI Ek } \\
\text { Oktober -De }\end{array}$ & $\begin{array}{r}K \\
\text { Isif di } \mathbf{K} \\
\text { ber } 201\end{array}$ & $\begin{array}{l}\text { berhasilan } \\
\text { Soegiarti }\end{array}$ \\
\hline $\begin{array}{l}\mathbf{N} \\
\mathbf{o}\end{array}$ & $\begin{array}{l}\text { keberhasilan } \\
\text { pemberian } \\
\text { ASI } \\
\text { Eksklusif }\end{array}$ & Jumlah & $\begin{array}{c}\text { Prosentasi } \\
(\%)\end{array}$ \\
\hline 1 & Ya & 16 & 64 \\
\hline 2 & Tidak & 9 & 36 \\
\hline & Jumlah & 25 & 100 \\
\hline
\end{tabular}

Sumber : Data Primer, 2015

Berdasarkan tabel 4.9 di atas menunjukkan dari 25 responden sebagian besar responden berhasil memberikan ASI Eksklusif sebanyak 16 responden (64\%).

Target nasional yang ditetapkan oleh pemerintah sebesar $80 \%$ untuk pemberian ASI eksklusif, maka dalam hal ini masih belum tercapai sesuai dengan harapan. Namun demikian hasil ini masih lebih tinggi jika dibandingkan dengan cakupan bayi yang mendapatkan ASI eksklusif di Jawa Timur sebesar $30,72 \%$ dan cakupan bayi yang mendapat ASI eksklusif di Surabaya tahun 2010, sebesar 26,90\%.( Profil Kesehatan Jawa Timur,2010)). Peran Bidan Khususnya di Rumah Sakit atau Rumah Bersalin dimana ibu ditolong dalam melahirkan sangat menentukan tentang cara memberi ASI yang baik. Bidan atau petugas kesehatan hendaknya mulai menyadari bahwa mereka berperan penting didalam membantu seorang ibu untuk menyusui dengan benar. Di Rumah Sakit atau tempat persalinan ibu, petugas kesehatan akan memberikan penerangan mengenai pemberian ASI yang pertama keluar ((colostrum), penyuluhan mengenai cara merawat dan membersihkan payudara,dan nasehat tentang gizi ibu menyusui.

Menurut Utami Roesli, 2007, ada 7 faktor yang mempengaruhi keberhasilan pemberian ASI Eksklusif, yaitu : 1) mempersiapkan payudara, bila diperlukan, 2) mempelajari ASI atau tata laksana menyusui, 3) menciptakan dukungan suami, 4) memilih tempat melahirkan yang "sayang bayi" seperti rumah sakit sayang bayi "atau" rumah bersalin sayang bayi", 5) memilih tenaga kesehatan yang mendukung pemberian ASI secara eksklusif, 6) mencari ahli persoalan menyusui seperti "klinik laktasi" atau konsultasi laktasi ( lactasion consultant) untuk persiapan apabila ibu meneteki menemui kesukaran, 7) menciptakan suasana sikap yang positif tentang ASI.

Banyaknya responden yang memberikan ASI Eksklusif kemungkinan disebabkan oleh beberapa faktor antara lain umur ibu,semakin matang umur ibu,maka proporsi menyusui ASI Eksklusif semakin besar.Sedangkan ibu yang memiliki umur yang kurang matang maka proporsi ibu untuk menyusui ASI eksklusif semakin kecil. Hal ini didukung dengan hasil penelitian yang menunjukkan umur ibu menyusui yang datang di RB Soegiarti paling banyak berumur 20-30 tahun( 52\%), umur $>30 \%$ sebesar $40 \%$,sedangkan yang berumur $<20$ tahun sebanyak 8\%. Faktor paritas juga mempengaruhi penggunaan ASI Eksklusif, dimana semakin bertambahnya anak maka semakin besar proporsi ibu untuk memberikan ASI Eksklusif keadaan ini didukung oleh paritas ibu paling besar adalah multigravida (52\%). Tingkat pendidikan responden juga berkontribusi secara tidak langsung terhadap 
tingginya angka cakupan ASI eksklusif, karena seseorang dengan tingkat pendidikan tinggi biasanya mempunyai pengetahuan yang lebih baik. Hasil penelitian menunjukkan bahwa pendidikan ibu menyusui yang datang ke RB Soegiarti terbanyak adalah berpendidikan SMA (40\%).

3. Analisis Dukungan Suami terhadap Keberhasilan ASI Eksklusif

Tabel 10 Tabulasi Silang Dukungan Suami Terhadap Keberhasilan Pemberian ASI Eksklusif di RB Soegiarti bulan Oktober - Desember 2015.

\begin{tabular}{|c|c|c|c|c|c|c|c|}
\hline \multirow{3}{*}{\multicolumn{2}{|c|}{\begin{tabular}{|ll} 
No & Keberhasilan \\
& Pemberian ASI \\
& Eksklusiff \\
& \\
\end{tabular}}} & \multicolumn{4}{|c|}{$\begin{array}{c}\text { Dukungan Suami } \\
\text { Terhadap Keberhasilan } \\
\text { Pemberian ASI Eksklusif }\end{array}$} & \multirow{2}{*}{\multicolumn{2}{|c|}{ Jumlah }} \\
\hline & & \multicolumn{2}{|c|}{$\mathrm{Ya}_{\mathrm{a}}$} & \multicolumn{2}{|c|}{ Tidak } & & \\
\hline & & $n$ & $\%$ & $n$ & $\%$ & $n$ & $\%$ \\
\hline 1 & Ya & 12 & 75 & 4 & 25 & 16 & 100 \\
\hline 2 & Jidak & 2 & 8 & 7 & 28 & 9 & 100 \\
\hline
\end{tabular}

Berdasarkan tabel 4.10 di atas menunjukkan keberhasilan pemberian ASI Eksklusif terbanyak dari 16 responden (64 $\%$ ) yang mendapat dukungan suami sebanyak 12 responden $(75 \%)$. Sedangkan ketidak berhasilan pemberian ASI Eksklusif terbanyak dari 9 responden (36\%) yang tidak mendapat dukungan sebanyak 7 responden $(28 \%)$.

\section{Hasil Analisis Data}

\begin{tabular}{|c|c|c|c|}
\hline \multirow[t]{2}{*}{$\begin{array}{l}\text { Keberhasilan } \\
\text { ASI Eksklusif }\end{array}$} & \multicolumn{2}{|c|}{$\begin{array}{l}\text { Dukungan Suami Terhadap } \\
\text { Keberhasilan ASI Eksklusif }\end{array}$} & \multirow{2}{*}{ Jumlah } \\
\hline & Teratur & Tidak Teratur & \\
\hline $\mathrm{Ya}$ & 12 & 4 & 16 \\
\hline Tidak & & & 9 \\
\hline Jumlah & 14 & 11 & 25 \\
\hline
\end{tabular}

Setelah dilakukan Uji Chi-Kuadrat pada tabel dapat disimpulkan $\quad \chi^{2}$ hitung $6,5>\chi^{2} \mathrm{t}_{\text {abel }}$ 3,841 , maka Hi diterima Ho ditolak yang berarti ada pengaruh dukungan suami terhadap keberhasilan pemberian ASI Eksklusif.
Setelah dilakukan Uji Chi-Square pada tabel dapat disimpulkan $\quad \chi_{\text {hitung }}^{2} 6,5>\chi_{\text {tabel }}^{2}$ 3,841 , maka Hi diterima Ho ditolak yang berarti ada pengaruh dukungan suami terhadap keberhasilan pemberian ASI Eksklusif.

Dukungan suami berpengaruh terhadap keberhasilan pemberian ASI Eksklusif, dimana menurut Utami Roesli, 2007, ada 7 faktor yang mempengaruhi keberhasilan pemberian ASI Eksklusif, yaitu : 1) mempersiapkan payudara, bila diperlukan, 2) mempelajari ASI atau tata laksana menyusui, 3) menciptakan dukungan suami , 4) memilih tempat melahirkan yang "sayang bayi" seperti rumah sakit sayang bayi "atau" rumah bersalin sayang bayi", 5) memilih tenaga kesehatan yang mendukung pemberian ASI secara eksklusif, 6) mencari ahli persoalan menyusui seperti "klinik laktasi" atau konsultasi laktasi (lactasion consultant) untuk persiapan apabila ibu meneteki menemui kesukaran, 7) menciptakan suasana sikap yang positif tentang ASI.

Namun masih ada ketidak berhasilan pemberian ASI Eksklusif terbanyak dari 9 responden $(36 \%)$ yang tidak mendapat dukungan sebanyak 7 responden (28\%), kemungkinan disebabkan karena kesibukan suami ditempat kerja serta pengetahuan suami tentang ASI Eksklusif cukup, hal ini didukung oleh semua suami ibu menyusui bayi usia $\geq 6$ bulan di RB Soegiarti bekerja dan pendidikan terakhir sebagian besar SMA

\section{SIMPULAN DAN SARAN}

Berdasarkan hasil penelitian yang telah dilakukan di RB Soegiarti bulan Oktober sampai Desember2015, dapat di simpulkan sebagai berikut :

1. Sebagian besar mendapatkan dukungan dari suami.

2. Sebagian besar berhasil memberikan ASI Eksklusif.

3. Ada pengaruh dukungan suami terhadap keberhasilan pemberian ASI Esklusif.

Berdasarkan analisis data dan simpulan, maka diajukan saran sebagai berikut :

1. Bagi ibu - ibu yang sedang menyusui dianjurkan untuk memberikan ASI eksklusif selama minimal sampai bayi berusia 6 bulan. 
2. Bagi suami dianjurkan untuk terus memberikan dukungan saat istri menyusui bayinya.

3. Bagi petugas kesehatan hendaknya meningkatkan pemberian penyuluhan tentang pemberian dan manfaat ASI Eksklusif, serta membantu ibu apabila mengalami kesulitan saat menyusui.

\section{DAFTAR PUSTAKA}

Ambarwati, Eny Retna dan Wulandari, Diah. 2008. Asuhan Kebidanan Nifas. Yogyakarta : Mitra Cendikia

Afiati, Eva Nur. 2007. Breastfeeding Father. Rabu, $\quad 15 \quad$ Agustus 2007. http://breasfeedingfather.co.id

Dinas Kesehatan Kota Surabaya, 2010. Profil Kesehatan Kota Surabaya Tahun 2010.

Dinas Kesehatan Propinsi Jawa Timur, 2010. Profil Kesehatan Propinsi Jawa Timur Tahun 2010.

Evy. 2008. Dukungan Ayah Dalam Praktik Pemberian ASI Masih Minim. Jumat, 11 Januari 2008. http://kompas.com

Hidayat, A. Aziz Alimut. 2008. Metode Penelitian Keperawatan dan Teknik Analisis Data. Jakarta : Salemba Medika

Rosita, Syarifah. 2008. ASI Untuk Kecerdasan Bayi. Yogyakarta : Ayyana

Roesli, Utami. 2007. Mengenal ASI Eksklusif. Jakarta : Trubus Agriwidya

Soetiningsih. 1997. ASI Petunjuk Untuk Tenaga Kesehatan. Jakarta : EGC

Suradi, Ruslina dan Roesli, Utami. 2008.

Manfaat ASI dan Menyusui. Jakarta : Balai penerbit FKUI

Muba, Wang, 2009. Sumber - Sumber Dukungan Suami. http://wangmuba.co

Zulfayeni. 2008. Dukungan Pelayanan Kesehatan Terhadap Pemberian ASI Eksklusif di Pekanbaru. Rabu, 19 November 2008. http://zulfayeni.wordpress.com 